\title{
Income-related health inequalities across regions in Korea
}

Eunju Hong ${ }^{1}$ and Byung Chul Ahn ${ }^{2^{*}}$

\begin{abstract}
Introduction: In addition to economic inequalities, there has been growing concern over socioeconomic inequalities in health across income levels and/or regions. This study measures income-related health inequalities within and between regions and assesses the possibility of convergence of socioeconomic inequalities in health as regional incomes converge.
\end{abstract}

Methods: We considered a total of 45,233 subjects ( $\geq 19$ years) drawn from the four waves of the Korean National Health and Nutrition Examination Survey (KNHANES). We considered true health as a latent variable following a lognormal distribution. We obtained ill-health scores by matching self-rated health (SRH) to its distribution and used the Gini Coefficient (GC) and an income-related ill-health Concentration Index (CI) to examine inequalities in income and health, respectively.

Results: The GC estimates were 0.3763 and 0.0657 for overall and spatial inequalities, respectively. The overall Cl was -0.1309 , and the spatial $\mathrm{Cl}$ was -0.0473 . The spatial GC and Cl estimates were smaller than their counterparts, indicating substantial inequalities in income (from 0.3199 in Daejeon to 0.4233 Chungnam) and income-related health inequalities (from -0.1596 in Jeju and -0.0844 in Ulsan) within regions.

The results indicate a positive relationship between the GC and the average ill-health and a negative relationship between the $\mathrm{Cl}$ and the average ill-health. Those regions with a low level of health tended to show an unequal distribution of income and health. In addition, there was a negative relationship between the $\mathrm{GC}$ and the $\mathrm{Cl}$, that is, the larger the income inequalities, the larger the health inequalities were. The GC was negatively related to the average regional income, indicating that an increase in a region's average income reduced income inequalities in the region. On the other hand, the $\mathrm{Cl}$ showed a positive relationship, indicating that an increase in a region's average income reduced health inequalities in the region.

Conclusion: The results suggest that reducing health inequalities across regions require a more equitable distribution of income and a higher level of average income and that the higher the region's average income, the smaller its health inequalities are.

Keywords: Bootstrapping, Gini Coefficient, Health Inequality, Convergence, Self-Rated Health, Concentration Index

\section{Introduction}

Socioeconomic inequalities have represented one of the most controversial issues in Korea, mainly because Korea has achieved considerable economic growth much faster than most other countries, resulting in a substantially unequal distribution of income opportunities, education and health care resources, among others, within

\footnotetext{
* Correspondence: bahn@yu.ac.kr

${ }^{2}$ School of Economics and Finance, Yeungnam University 280 Daehak-ro Kyungsan-si, Kyungbuk 712-749 Korea

Full list of author information is available at the end of the article
}

and between regions. For example, population density varies considerably across the country. The capital region (Seoul, Gyeonggi, and Incheon) accounts for only $11.8 \%$ of the land but accommodates approximately half of Korea's total population (48.2\%; 22.8 million). In particular, Seoul (the capital) has a population of 9.8 million $(20.8 \%)$, although it accounts for only $0.6 \%$ of the land. As of 2006, 51.8\% of all manufacturers in Korea, which accounted for $48.5 \%$ of national employment, were based in the capital region [1]. Few large firms are headquartered outside the capital region, indicating a

\section{Biomed Central}


lack of attractive jobs available to local residents. Further, there exist substantial socioeconomic inequalities across regions outside the capital region, which have depended largely on differences in the level of industrialization across regions.

Such socioeconomic inequalities across regions have provoked a fierce policy debate searching for more equitability in various social dimensions, and thus, economic concentration, real estate bubbles, inequalities in education, and poor accessibility to medical resources/ public health-care systems have been important buzz words in the media. The previous Rho administration (2003-2008) even initiated a policy initiative to relocate the capital and transfer some of the commercial resources and public enterprises from the capital region to underdeveloped regions to reduce the country's socioeconomic inequalities. This initiative was the subject of much political and legal debate. The competition among regions to secure limited resources and attract government corporations has been intensifying. Proponents argued that the policy would lessen regional conflicts and promote economic as well as social equality across regions. On the other hand, opponents brought this policy to the constitutional court, arguing that it was motivated more by political populism than by social justice and economic efficiency. After a long legal discussion, the court decided against the relocation of the capital but upheld the notion of spreading public organizations across the country.

In addition to the widespread economic inequalities that triggered the aforementioned political and legal debate, there has been growing concern over inequalities in public welfare, particularly those in inequalities in health across income levels and/or regions. Korea has witnessed substantial differences in health indicators across regions. For example, the mortality rate tends to be higher in low-income regions than in high-income ones [2]. Such differences, together with the aging population, have been a major source of concern over the public's health and access to adequate health care.

Health-care resources have been unevenly distributed across regions and highly concentrated in certain areas. As of 2009 , Seoul accounted for $27.6 \%$ of medical specialists and $52.4 \%$ of physicians and dentists. Further, the capital region accounted for most of the high-tech medical equipment [3]. Consequently, medical expenditures are highly concentrated in the capital region. In 2008, Seoul accounted for $26.9 \%$ of all insured medical bills, and regions outside Seoul and the capital region accounted for $36.2 \%$ and $14.5 \%$, respectively [4]. Between 2006 and 2008, half of the revenues generated by the top 20 general hospitals in Seoul were from patients residing outside Seoul [5]. This may be because hospitals in Seoul tend to be much better equipped than those in other regions and because Seoul has a more convenient and efficient transportation system.

This concentration can lead to the inefficient use of individual and national resources and exacerbate socioeconomic inequalities in health across regions. Previous studies have found income-related inequalities in health in various countries, including those in Europe [6,7], the U.K. [8], the U.S. [7,9], China [10-14], and Korea [15], among others. Thus, achieving income growth and reducing inequalities in health have become important national issues for many countries, including EU members [16]. Hence, various economic policies have been proposed to address these issues. In this regard, the present study examines whether an increase in regional income could reduce socioeconomic inequalities in health across regions.

Socioeconomic inequalities in health can be examined in many ways, including the concentration index (CI), which is an effective tool for measuring social inequalities in health [17] and has been referred to as a "workhorse in most health economic studies" [18]. The CI measures socioeconomic inequalities in health by taking into account individuals' level of health and rank in the socioeconomic domain [19]. The Gini coefficient (GC) measures socioeconomic inequalities in income by taking into account individuals' income level and income rank. As indicated in the Data and Methods section, the $\mathrm{CI}$ and the GC are virtually identical in that they have the same formula (except for some differences in the attributes that they attempt to address).

The present paper focuses on income-related inequalities in health in Korea. Specifically, the paper estimates socioeconomic inequalities in income and incomerelated inequalities in health for the whole population as well as within/across regions by using the GC and the CI, respectively. In addition, the paper examines the relationship between these inequalities across regions. Based on the results, the paper examines whether socioeconomic inequalities in health across regions would converge (given a convergence of regional income to a higher level of income) and provides policy implications for the more equitable distribution of health.

\section{Data and methods}

The data were drawn from the Korea National Health and Nutrition Examination Survey (KNHANES), a comprehensive and representative survey conducted every three years by the Korea Center for Disease Control and Prevention (KCDC) to assess the health of the Korean population. The survey uses household registries to collect data from a stratified multistage probability random sample based on geographic regions, administrative districts, and types of residences. KNHANES provides demographic, socioeconomic, and 
dietary information as well as medical history information collected via personal interviews. Four waves (1998, 2001, 2005 and 2007) of KNHANES surveys are available. The first three surveyed samples over a couple of months during the survey year. However, the fourth wave employed three independent samples and extended the survey period to the entire year for all three years by considering one circulatory sample for each year. Hence, the data from the 2007 survey covered only one fifth of the sample surveyed in the fourth wave. KCDC has yet to announce future data releases [20]. We considered a total of 45,233 subjects who were at least 19 (Table 1).
We adjusted household income by using a consumer price index (CPI $=100$ in 2005) for each region and calculated per capita income by dividing CPI-adjusted household income by family size. Those subjects providing no information on their income $(\mathrm{n}=1,460)$ were omitted, and the remaining 43,773 observations were used for the estimation of the GC and the $\mathrm{CI}$ and for the regression analysis for establishing the correlation between inequalities and income.

We assessed the subjects' health based on self-rated health (SRH). We asked the subjects a question about their health ("How would you rate your current health compared to that of others of your age?"), and they

Table 1 Distribution of gender and waves by region

\begin{tabular}{|c|c|c|c|c|c|c|c|c|c|c|}
\hline Region & & male & female & 1998 & 2001 & 2005 & 2007 & Total & Share $^{1)}$ & $\mathrm{Si} / \mathrm{Do}^{2)}$ \\
\hline \multirow[t]{2}{*}{ Gangwon } & $\mathrm{N}$ & 717 & 828 & 304 & 296 & 842 & 103 & 1545 & & Do \\
\hline & $\%$ & 1.59 & 1.83 & 0.67 & 0.65 & 1.86 & 0.23 & 3.42 & 3.1 & \\
\hline \multirow[t]{2}{*}{ Gyeonggi } & $\mathrm{N}$ & 3868 & 4371 & 1453 & 1510 & 4726 & 550 & 8239 & & Do \\
\hline & $\%$ & 8.55 & 9.66 & 3.21 & 3.34 & 10.45 & 1.22 & 18.21 & 22.03 & \\
\hline \multirow[t]{2}{*}{ Gyeongnam } & $\mathrm{N}$ & 1437 & 1729 & 838 & 465 & 1632 & 231 & 3166 & & Do \\
\hline & $\%$ & 3.18 & 3.82 & 1.85 & 1.03 & 3.61 & 0.51 & 7 & 6.46 & \\
\hline \multirow[t]{2}{*}{ Gyeongbuk } & $\mathrm{N}$ & 1201 & 1474 & 626 & 379 & 1415 & 255 & 2675 & & Do \\
\hline & $\%$ & 2.66 & 3.26 & 1.38 & 0.84 & 3.13 & 0.56 & 5.91 & 5.52 & \\
\hline \multirow[t]{2}{*}{ Gwangju } & $\mathrm{N}$ & 634 & 733 & 230 & 296 & 730 & 111 & 1367 & & $\mathrm{Si}$ \\
\hline & $\%$ & 1.4 & 1.62 & 0.51 & 0.65 & 1.61 & 0.25 & 3.02 & 3 & \\
\hline \multirow[t]{2}{*}{ Daegu } & $\mathrm{N}$ & 1026 & 1281 & 464 & 411 & 1249 & 183 & 2307 & & $\mathrm{Si}$ \\
\hline & $\%$ & 2.27 & 2.83 & 1.03 & 0.91 & 2.76 & 0.4 & 5.1 & 5.21 & \\
\hline \multirow[t]{2}{*}{ Daejeon } & $\mathrm{N}$ & 606 & 709 & 176 & 254 & 789 & 96 & 1315 & & $\mathrm{Si}$ \\
\hline & $\%$ & 1.34 & 1.57 & 0.39 & 0.56 & 1.74 & 0.21 & 2.91 & 3.05 & \\
\hline \multirow[t]{2}{*}{ Busan } & $\mathrm{N}$ & 1658 & 1996 & 740 & 626 & 2106 & 182 & 3654 & & $\mathrm{Si}$ \\
\hline & $\%$ & 3.67 & 4.41 & 1.64 & 1.38 & 4.66 & 0.4 & 8.08 & 7.45 & \\
\hline \multirow[t]{2}{*}{ Seoul } & $\mathrm{N}$ & 4242 & 5011 & 1749 & 1768 & 5239 & 497 & 9253 & & $\mathrm{Si}$ \\
\hline & $\%$ & 9.38 & 11.08 & 3.87 & 3.91 & 11.58 & 1.1 & 20.46 & 20.77 & \\
\hline \multirow[t]{2}{*}{ Ulsan } & $\mathrm{N}$ & 436 & 496 & $90^{3)}$ & 194 & 591 & 57 & 932 & & $\mathrm{Si}$ \\
\hline & $\%$ & 0.96 & 1.1 & 0.2 & 0.43 & 1.31 & 0.13 & 2.06 & 2.22 & \\
\hline \multirow[t]{2}{*}{ Incheon } & $\mathrm{N}$ & 1011 & 1145 & 339 & 398 & 1276 & 143 & 2156 & & $\mathrm{Si}$ \\
\hline & $\%$ & 2.24 & 2.53 & 0.75 & 0.88 & 2.82 & 0.32 & 4.77 & 5.35 & \\
\hline \multirow[t]{2}{*}{ Jeonnam } & $\mathrm{N}$ & 912 & 1091 & 503 & 309 & 1026 & 165 & 2003 & & Do \\
\hline & $\%$ & 2.02 & 2.41 & 1.11 & 0.68 & 2.27 & 0.36 & 4.43 & 3.85 & \\
\hline \multirow[t]{2}{*}{ Jeonbuk } & $\mathrm{N}$ & 1026 & 1226 & 469 & 403 & 1291 & 89 & 2252 & & Do \\
\hline & $\%$ & 2.27 & 2.71 & 1.04 & 0.89 & 2.85 & 0.2 & 4.98 & 3.77 & \\
\hline \multirow[t]{2}{*}{ Jeju } & $\mathrm{N}$ & 413 & 460 & 94 & 154 & 551 & 74 & 873 & & Do \\
\hline & $\%$ & 0.91 & 1.02 & 0.21 & 0.34 & 1.22 & 0.16 & 1.93 & 1.13 & \\
\hline \multirow[t]{2}{*}{ Chungnam } & $\mathrm{N}$ & 886 & 1030 & 527 & 304 & 948 & 137 & 1916 & & Do \\
\hline & $\%$ & 1.96 & 2.28 & 1.17 & 0.67 & 2.1 & 0.3 & 4.24 & 4 & \\
\hline \multirow[t]{2}{*}{ Chungbuk } & $\mathrm{N}$ & 736 & 844 & 389 & 299 & 785 & 107 & 1580 & & Do \\
\hline & $\%$ & 1.63 & 1.87 & 0.86 & 0.66 & 1.74 & 0.24 & 3.49 & 3.09 & \\
\hline \multirow[t]{2}{*}{ Total } & $\mathrm{N}$ & 20809 & 24424 & 8991 & 8066 & 25196 & 2980 & 45233 & & \\
\hline & $\%$ & 46 & 54 & 19.88 & 17.83 & 55.7 & 6.59 & 100 & & \\
\hline
\end{tabular}

1) Each region's share of Korea's population based on the national census in 2005 .

2) Si and Do denote autonomous metropolitan cities and provinces, respectively.

3) Subjects for Ulsan for 1998 were re-coded from the initial classification of Gyeongnam. 
rated their health on a scale ranging from (1) very healthy" to (5) very unhealthy." We considered true health is a continuous latent variable following a standard lognormal distribution underlying the self-rated health status. We obtained ill-health scores for each category by matching the cumulative sample proportion to the probability of the standard lognormal distribution. To control for the effects of the subjects' age and gender, we standardized the raw scores indirectly by substituting age/gender average scores (excluding the subject's own score) for individual scores [6].

We assessed the extent of inequalities in income and health by using the GC and the ill-health $\mathrm{CI}$, respectively. The GC, a popular measure of inequalities in income, refers to the ratio of the area that lies between the line of equality and the Lorenz curve, which plots the cumulative proportion of the total income of the population to the cumulative proportion of population (beginning with the lowest income group or individual). We used the CI to summarize income-related inequalities in health and measured these inequalities by the area between the line of equality and the ill-health concentration curve, which displayed the cumulative proportion of ill-health to the cumulative proportion of the population by per capita income (beginning with the most disadvantaged populations). This CI ranged from positive to negative values depending on whether the curve fell below or above the diagonal, respectively. If the $\mathrm{CI}$ was 0 , then we assumed perfect equality. If $\mathrm{CI}>$ 0 (or $<0$ ), then we assumed that ill-health were concentrated in the highest (or lowest) socioeconomic groups. The absolute value of the CI indicated the extent of income-related inequalities in health.

The GC and the CI were obtained as follows:

$$
C=\frac{2}{n \bar{x}} \sum_{i=1}^{n} x_{i} R_{i}-1 \text {, }
$$

where $\bar{x}$ denotes the average income and the average ill-health scores for the GC and the CI, respectively, and $R_{i}$ indicates the relative ranking of the $\mathrm{i}$-th individual/ group/region (beginning with the individual/group/ region with the lowest income). We calculated the inequalities in income and health across regions by using $\mathrm{C}$ and called these inequalities "spatial inequalities."

Although standard errors associated with the GC and the $\mathrm{CI}$ can obtained using various assumptions and methods [7,21-24], they are seldom reported because of mathematical difficulties or heavy computational burdens [22]. In this study, we employed bootstrapping, a distribution-free simulation-based method, to estimate the $\mathrm{CI}$ and its confidence intervals. We obtained the $\mathrm{GC} / \mathrm{CI}$ percentiles from bootstrapping with 1,000 replications and employed the t-test to examine gender differences in health scores. Further, we conducted a regression analysis with appropriate weights to evaluate the relationships among the level of income, income inequalities, and socioeconomic inequalities in health. We used SAS Version 9.0 (SAS Institute Inc., Cary, NC, USA) for all the analyses.

\section{Results}

Tables 1, 2, 3 and 4 present the subjects' gender, mean age, and income as well as the share of older individuals and the waves by region. The results indicate that $46.4 \%$ of the subjects resided in cities $(\mathrm{Si})$, which is consistent with the national average (47.5\%) (Table 1). Jeonnam was the oldest province, with the mean age of $51.8 \pm$ 16.7 (SD), whereas Ulsan was the youngest, with the mean age of $41.5 \pm 14.4$ (Table 2). Specifically, 26.6\% and $16.4 \%$ of the subjects in Jeonnam were 65 and above and 70 and above, respectively, whereas only $8.7 \%$ of those in Ulsan were 65 and above (Table 2). Ulsan showed the highest average income, whereas Jeonnam, the lowest (Table 3).

Table 4 shows the distribution of SRH by region. Gwangju had the highest percentage of very healthy subjects (7.83\%), and Gyeongbuk, the lowest (3.10\%). On the other hand, Chungnam had the highest percentage of very unhealthy subjects, whereas Daejeon, the lowest (2.05\%). Overall, $4.79 \%$ of all subjects responded that they were very healthy, and $3.24 \%$, very unhealthy.

Table 2 Mean age and proportion of older individuals by region

\begin{tabular}{llllllll}
\hline Region & & & \multicolumn{3}{c}{ Elderly, $\geq 65$} & \multicolumn{2}{c}{ Elderly, $\geq 70$} \\
\cline { 6 - 9 } & $\mathbf{N}$ & average & SD & $\mathbf{N}$ & $\%$ & $\mathbf{N}$ & $\%$ \\
\hline Gangwon & 1545 & 49.1 & 15.9 & 299 & 19.4 & 160 & 10.4 \\
Gyeonggi & 8239 & 43.2 & 15.0 & 949 & 11.5 & 567 & 6.9 \\
Gyeongnam & 3166 & 45.5 & 15.9 & 465 & 14.7 & 291 & 9.2 \\
Gyeongbuk & 2675 & 50.2 & 17.1 & 651 & 24.3 & 423 & 15.8 \\
Gwangju & 1367 & 43.3 & 15.8 & 159 & 11.6 & 103 & 7.5 \\
Daegu & 2307 & 43.7 & 15.6 & 270 & 11.7 & 158 & 6.8 \\
Daejeon & 1315 & 44.6 & 15.4 & 170 & 12.9 & 87 & 6.6 \\
Busan & 3654 & 44.0 & 15.3 & 408 & 11.2 & 233 & 6.4 \\
Seoul & 9253 & 42.9 & 15.3 & 955 & 10.3 & 543 & 5.9 \\
Ulsan & 932 & 41.5 & 14.4 & 81 & 8.7 & 46 & 4.9 \\
Incheon & 2156 & 43.0 & 15.0 & 242 & 11.2 & 149 & 6.9 \\
Jeonnam & 2003 & 51.8 & 16.7 & 532 & 26.6 & 328 & 16.4 \\
Jeonbuk & 2252 & 47.6 & 16.6 & 413 & 18.3 & 248 & 11.0 \\
Jeju & 873 & 46.4 & 16.5 & 140 & 16.0 & 88 & 10.1 \\
Chungnam & 1916 & 48.9 & 16.9 & 441 & 23.0 & 247 & 12.9 \\
Chungbuk & 1580 & 47.0 & 16.4 & 274 & 17.3 & 163 & 10.3 \\
\hline Total & 45233 & 45.0 & 15.9 & 6449 & 14.3 & 3834 & 8.5 \\
\hline
\end{tabular}

SD: Standard deviation. 
Table 3 Average per capita income by region

\begin{tabular}{lllll}
\hline Region & $\mathbf{N}$ & Income & SD & rank \\
\hline Gangwon & 1519 & 61.7 & 50.4 & 11 \\
Gyeonggi & 7924 & 71.9 & 51.0 & 3 \\
Gyeongnam & 3051 & 59.6 & 48.8 & 14 \\
Gyeongbuk & 2544 & 59.3 & 54.6 & 15 \\
Gwangju & 1336 & 63.8 & 48.3 & 8 \\
Daegu & 2213 & 61.5 & 45.1 & 12 \\
Daejeon & 1265 & 70.0 & 44.9 & 4 \\
Busan & 3599 & 61.2 & 44.4 & 13 \\
Seoul & 8899 & 79.3 & 58.9 & 2 \\
Ulsan & 911 & 83.6 & 58.4 & 1 \\
Incheon & 2109 & 68.9 & 48.7 & 5 \\
Jeonnam & 1947 & 53.8 & 50.2 & 16 \\
Jeonbuk & 2239 & 64.3 & 48.3 & 7 \\
Jeju & 852 & 64.5 & 48.4 & 6 \\
Chungnam & 1832 & 62.5 & 57.1 & 10 \\
Chungbuk & 1533 & 63.2 & 54.7 & 9 \\
\hline Total & 43773 & 67.8 & 52.6 & \\
\hline SD: Standard & & & &
\end{tabular}

SD: Standard deviation.

Income measured in 10,000 KRW.

Figure 1 shows gender differences in health, and Figure 2 shows SRH scores by age group. The results indicate substantial differences in health. Male subjects were healthier than their female counterparts. Further, younger subjects were healthier than older ones. Figure 3 shows the average ill-health scores plotted against average regional income for 16 regions. High-income regions were healthier than low-income ones.

Figure 4 shows the average (raw and standardized) illhealth scores by income group. The regression line for the standardized ill-health score was $(p=0.0125)$ :

$$
\text { ill }- \text { health }=1.6937-0.0265 \times \text { income, } R^{2}=0.5620 \text {. }
$$

The results indicate that high-income groups were healthier than low-income ones, which is consistent with the findings of previous studies demonstrating the positive income elasticity of health [2,6-18].

Table 5 summarizes the inequality measures for various cases. The upper part of Table 5 shows the overall inequalities in income (GC) and health $\left(\mathrm{CI}, \mathrm{CI}^{*}\right)$ for the whole sample. The lower part indicates the inequalities in income $(\mathrm{GC})$ and health $\left(\mathrm{CI}, \mathrm{CI}^{*}\right)$ across 16 regions. Here $\mathrm{CI}^{*}$ denotes the CI obtained from gender/ageadjusted ill-health scores based on the indirect standardization in Kakwani et al [6]. The GC was 0.3763 for overall and 0.0657 for spatial inequalities. The incomerelated CI was -0.1309 for overall and -0.0473 for spatial inequalities. The overall GC ranged from 0.356 to 0.407 across waves, and the CI, from -0.1011 to -0.1484 .

Table 6 shows the within-region inequalities in income and health for 16 regions. Gyeongbuk showed the highest ill-health (1.859), and Incheon, the lowest ill-health (1.355). The relationship between ill-health scores and income was estimated across 16 regions by using the data as follows $(p<0.001)$ :

$$
\text { ill }- \text { health }=2.5215-0.1482 \times \text { income, } R^{2}=0.5855 \text {. }
$$

The regression estimates indicate a significant relationship between ill-health scores and income across regions. High-income regions were healthier than lowincome ones. Further, income level accounted for more than half of the total variation in ill-health scores across

Table 4 Self-rated health by region

\begin{tabular}{lllllll}
\hline Region & very healthy & healthy & fair & unhealthy & very unhealthy & Total \\
\hline Gangwon & $85(5.50)$ & $511(33.07)$ & $552(35.73)$ & $339(21.94)$ & $58(3.75)$ & 1545 \\
Gyeonggi & $373(4.53)$ & $3528(42.82)$ & $2902(35.22)$ & $1238(15.03)$ & $198(2.40)$ & 8239 \\
Gyeongnam & $127(4.01)$ & $1184(37.4)$ & $1103(34.84)$ & $622(19.65)$ & $130(4.11)$ & 3166 \\
Gyeongbuk & $83(3.10)$ & $811(30.32)$ & $939(35.10)$ & $727(27.18)$ & $115(4.30)$ & 2675 \\
Gwangju & $107(7.83)$ & $498(36.43)$ & $519(37.97)$ & $192(14.05)$ & $51(3.73)$ & 1367 \\
Daegu & $108(4.68)$ & $764(33.12)$ & $876(37.97)$ & $456(19.77)$ & $103(4.46)$ & 2307 \\
Daejeon & $61(4.64)$ & $504(38.33)$ & $510(38.78)$ & $213(16.20)$ & $27(2.05)$ & 1315 \\
Busan & $162(4.43)$ & $1295(35.44)$ & $1419(38.83)$ & $661(18.09)$ & $117(3.20)$ & 3654 \\
Seoul & $513(5.54)$ & $3777(40.82)$ & $3309(35.76)$ & $1403(15.16)$ & $251(2.71)$ & 9253 \\
Ulsan & $42(4.51)$ & $338(36.27)$ & $375(40.24)$ & $147(15.77)$ & $30(3.22)$ & 932 \\
Incheon & $130(6.03)$ & $894(41.47)$ & $764(35.44)$ & $315(14.61)$ & $53(2.46)$ & 2156 \\
Jeonnam & $88(4.39)$ & $735(36.69)$ & $624(31.15)$ & $472(23.56)$ & $84(4.19)$ & 2003 \\
Jeonbuk & $118(5.24)$ & $845(37.52)$ & $797(35.39)$ & $420(18.65)$ & $72(3.20)$ & 2252 \\
Jeju & $52(5.96)$ & $333(38.14)$ & $293(33.56)$ & $168(19.24)$ & $27(3.09)$ & 873 \\
Chungnam & $60(3.13)$ & $645(33.66)$ & $678(35.39)$ & $444(23.17)$ & $89(4.65)$ & 1916 \\
Chungbuk & $56(3.54)$ & $655(41.46)$ & $537(33.99)$ & $273(17.28)$ & $59(3.73)$ & 1580 \\
\hline Total & $2165(4.79)$ & $17317(38.28)$ & $16197(35.81)$ & $8090(17.89)$ & $1464(3.24)$ & 45233 \\
\hline
\end{tabular}

Numbers in parentheses indicate percentages. 


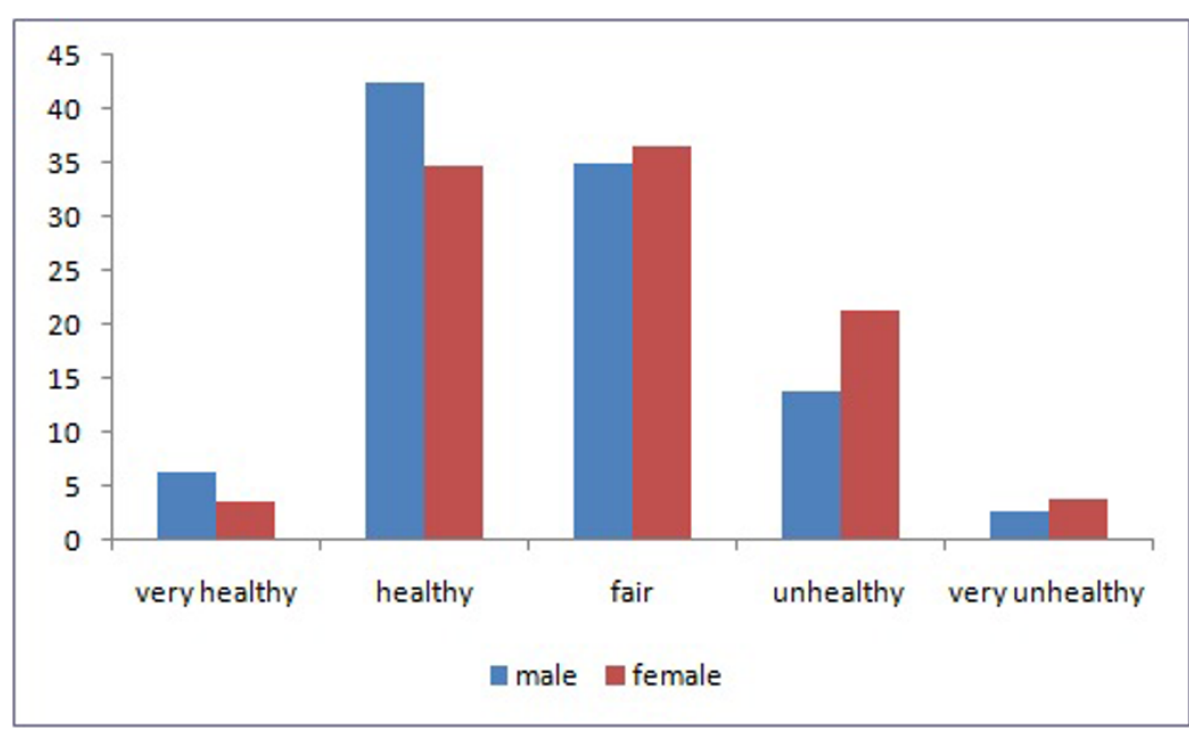

Figure 1 Self-reported health distribution by gender

income groups and regions. Both regressions had considerable explanatory power even when we did not control for other health factors such as socioeconomic status, regional characteristics, health resources, and health behaviors, which are well summarized in Fang et al [25].

Figure 5 plots the within-region GC and the withinregion $\mathrm{CI}$ against ill-health scores for 16 regions. The GC was positively related to ill-health, whereas the CI was negatively related. An increase in the average illhealth increased income and health inequalities across regions. Ill-health scores were positively correlated with income and health inequalities.

Table 7 shows the relationship between health inequalities and the level of level/income inequalities for 16 regions. As shown in Figure 6 (the scatter plot), the $\mathrm{GC}$ was negatively related to the level of income. The CI was positively related to the level of income, but the GC was negatively related. In particular, the results indicate a strong relationship between gender/age-adjusted inequalities in health $\left(\mathrm{CI}^{*}\right)$ and the average income as well as income inequalities (GC) with large $R^{2}$. An

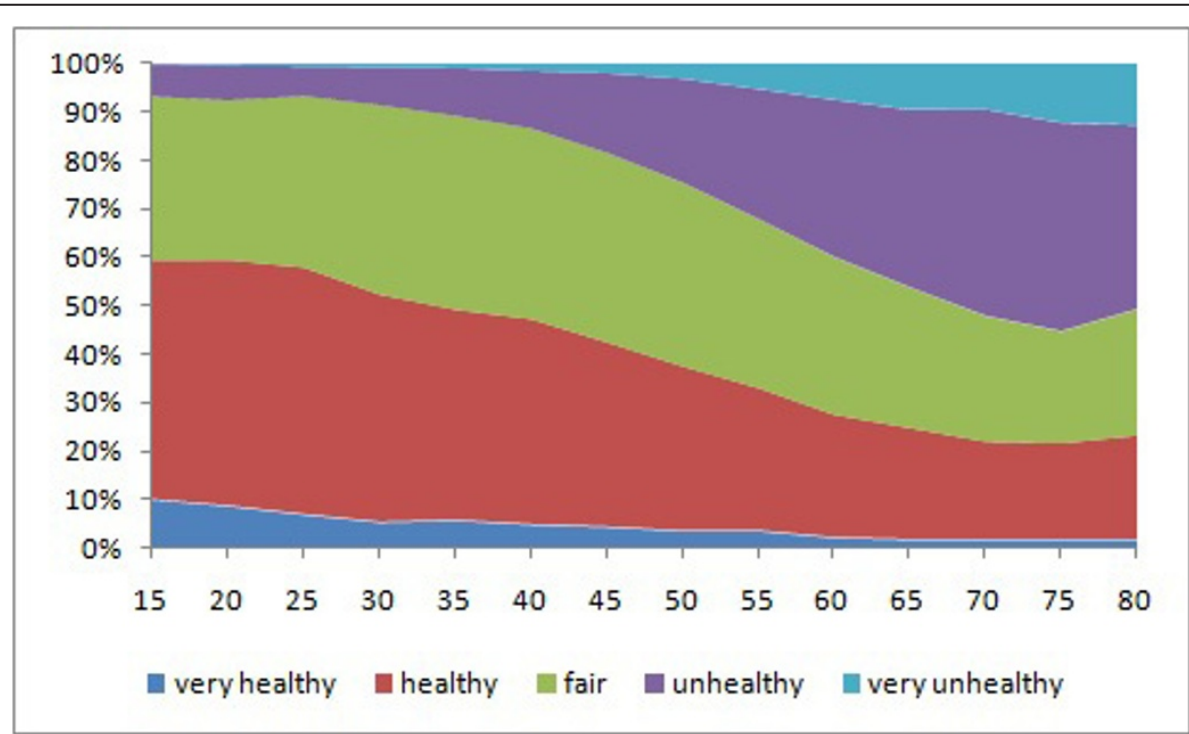

Figure 2 Self-reported health distribution by age group. The $x$-axis: Five-year age groups. 


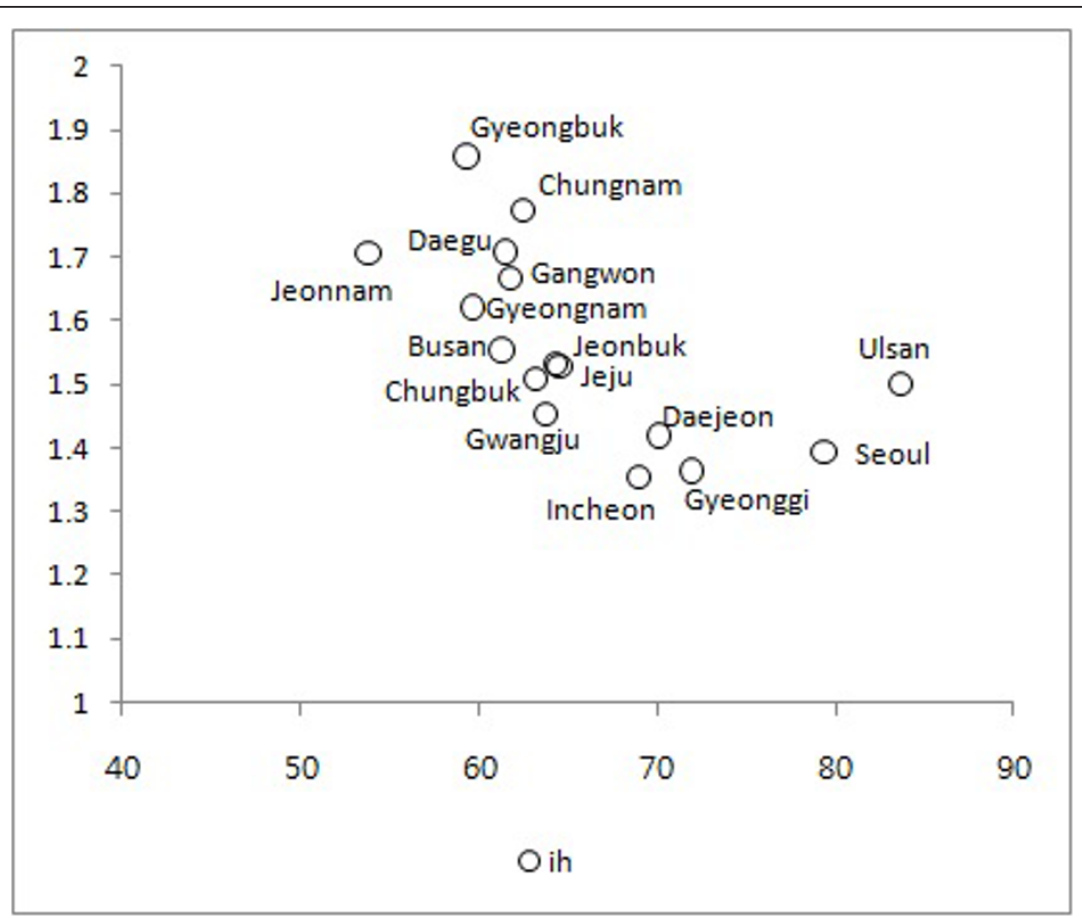

Figure 3 Average ill-health scores plotted against average regional income for 16 regions. The x-axis: Per capita income. The y-axis: IIIhealth scores.

increase in the region's average income reduced income inequalities and income-related inequalities in health.

\section{Discussion}

In addition to inequalities at the country level, those at the regional level reflect a major source of concern because they can trigger regional conflicts and thus destabilize the country. Together with the rapidly aging population and economic crises, inequalities in income and health both within and across regions have emerged as an important issue in Korea. Thus, finding ways to effectively reduce such inequalities has become an urgent task.

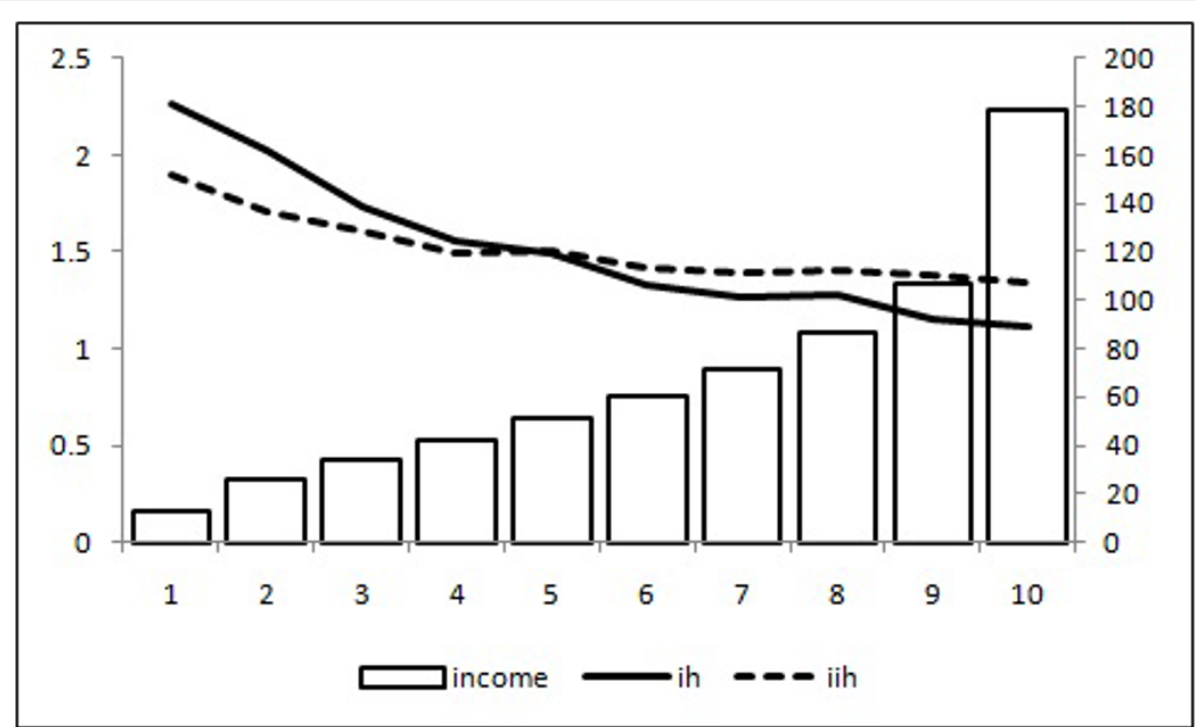

Figure 4 Average (raw and standardized) ill-health scores by income group. ih (left): Average ill-health scores for each income group. iih (left): Average ill-health scores standardized indirectly. income (right): Real per capita income. 
Table 5 Estimates of overall and spatial inequalities in income and health

\begin{tabular}{lllll}
\hline & Percentile & $\mathrm{GC}$ & $\mathrm{Cl}$ & $\mathrm{Cl}^{*}$ \\
\hline Overall inequalities & estimate & 0.3763 & -0.1309 & -0.0589 \\
& 0.005 & 0.3723 & -0.1378 & -0.0617 \\
& 0.025 & 0.3733 & -0.1365 & -0.0609 \\
& 0.05 & 0.3738 & -0.1356 & -0.0606 \\
& 0.5 & 0.3763 & -0.1308 & -0.0589 \\
& 0.95 & 0.3788 & -0.1265 & -0.0571 \\
& 0.975 & 0.3791 & -0.1255 & -0.0568 \\
Spatial inequalities & 0.995 & 0.3800 & -0.1239 & -0.0561 \\
\hline & estimate & 0.0657 & -0.0473 & -0.0282 \\
& 0.005 & 0.0624 & -0.0484 & -0.0291 \\
& 0.025 & 0.0629 & -0.0482 & -0.0290 \\
& 0.05 & 0.0631 & -0.0481 & -0.0289 \\
& 0.5 & 0.0646 & -0.0466 & -0.0279 \\
& 0.95 & 0.0654 & -0.0451 & -0.0272 \\
& 0.975 & 0.0655 & -0.0448 & -0.0271 \\
& 0.995 & 0.0656 & -0.0441 & -0.0268 \\
\hline
\end{tabular}

Spatial GC/Cl rankings are based on regional average income.

Spatial inequalities indicate the $\mathrm{GC}$ and the $\mathrm{Cl}$ calculated across regions.

Percentiles were obtained through bootstrapping simulations with 1,000 replications.

$\mathrm{Cl}$ : The $\mathrm{Cl}$ of ill-health scores.

$\mathrm{Cl}^{*}$ : The $\mathrm{Cl}$ of indirectly standardized ill-health scores by age and gender. GC: The Gini Coefficient.

In general, individuals' gender and age are important indicators of their health. Male subjects were healthier and had fewer health problems than their female counterparts. These results demonstrate gender differences in

Table 6 Inequalities in income and health within regions

\begin{tabular}{lllllll}
\hline Region & Income & III-health & GC & Cl & Cl* $^{*}$ & N \\
\hline Gangwon & 61.7 & 1.667 & 0.4008 & -0.1479 & -0.0732 & 1519 \\
Gyeonggi & 71.9 & 1.364 & 0.3488 & -0.1215 & -0.0497 & 7924 \\
Gyeongnam & 59.6 & 1.621 & 0.3914 & -0.1215 & -0.0631 & 3051 \\
Gyeongbuk & 59.3 & 1.859 & 0.4124 & -0.1192 & -0.0766 & 2544 \\
Gwangju & 63.8 & 1.454 & 0.3745 & -0.1187 & -0.0282 & 1336 \\
Daegu & 61.5 & 1.709 & 0.3555 & -0.1410 & -0.0438 & 2213 \\
Daejeon & 70.0 & 1.420 & 0.3199 & -0.1151 & -0.0254 & 1265 \\
Busan & 61.3 & 1.554 & 0.3535 & -0.0981 & -0.0439 & 3599 \\
Seoul & 79.3 & 1.393 & 0.3655 & -0.1234 & -0.0423 & 8899 \\
Ulsan & 83.6 & 1.501 & 0.3504 & -0.0844 & -0.0407 & 911 \\
Incheon & 68.9 & 1.355 & 0.3550 & -0.1293 & -0.0575 & 2019 \\
Jeonnam & 53.8 & 1.707 & 0.4231 & -0.1576 & -0.0846 & 1947 \\
Jeonbuk & 64.3 & 1.533 & 0.3753 & -0.1136 & -0.0538 & 2239 \\
Jeju & 64.5 & 1.528 & 0.3504 & -0.1596 & -0.0498 & 852 \\
Chungnam & 62.5 & 1.773 & 0.4233 & -0.1209 & -0.0634 & 1832 \\
Chungbuk & 63.2 & 1.508 & 0.4086 & -0.1076 & -0.0635 & 1533 \\
\hline
\end{tabular}

Income: The region's average per capita income.

III-health: Average ill-health scores.

$\mathrm{Cl}$ : The $\mathrm{Cl}$ of ill-health scores.

$\mathrm{Cl}^{*}$ : The $\mathrm{Cl}$ of indirectly standardized ill-health scores by age and gender GC: The Gini Coefficient. the health of individuals (Figure 1). The average illhealth score was 1.3417 for male subjects and 1.6657 for female subjects $(p<.0001)$. For all the waves, male subjects were healthier than their female counterparts.

There were substantial differences in the age of subjects across regions. The mean age varied from 41.5 for Ulsan to 51.8 for Jeonnam (Table 2). Older individuals (those 65 and over) accounted for more than 20\% of the subjects in Gyeongbuk, Jeonnam, and Chungnam, whereas they accounted for only $8.7 \%$ and $10.3 \%$ of the subjects in Ulsan and Seoul, respectively. In particular, Gyeongbuk and Jeonnam accounted for more than 15\% of those subjects 70 and above (Table 2).

The results indicate a close relationship between the subjects' age and health inequalities (Figure 2). Older individuals are more likely to have health problems and require health-care services than younger ones. Thus, without proper attention and care, age differences can lead to substantial health inequalities across the country as well as within/across regions. In this regard, Korea's rapidly aging population can accelerate health inequalities in the country, and thus, there is an urgent need for proper attention.

When dealing with health inequalities, socioeconomic factors represent a source of major policy concern. Jeonnam had the lowest per capita income, and Ulsan, the highest. Jeonnam was the oldest and the poorest, whereas Ulsan, the youngest and the richest. There were clear differences in the subject's age and income across regions (Tables 2 and 3).

The ill-health scores were lower for high-income groups than for low-income ones (Figure 4). The regression results indicate a significant negative relationship between ill-health scores and income. The level of income accounted for $56.2 \%$ of the total variation in illhealth.

The comparison of the subjects' health status across regions provides similar results. Ill-health scores were negatively related to the average income across regions (Figure 3). High-income regions were healthier than low-income ones $\left(p<0.001, R^{2}=0.5855\right)$. Both the overall and spatial regression estimates indicate a significant negative relationship between ill-health and income. These regressions explained more than half of the total variation in ill-health across income groups and regions.

These findings were independent of gender/age adjustment. For example, high-income groups and regions were healthier than low-income ones regardless of whether we controlled for gender and age effects, leaving a large portion of health status to be explained by socioeconomic and behavioral factors.

There was a strong relationship between gender/age adjusted health and income inequalities (Table 7). In 


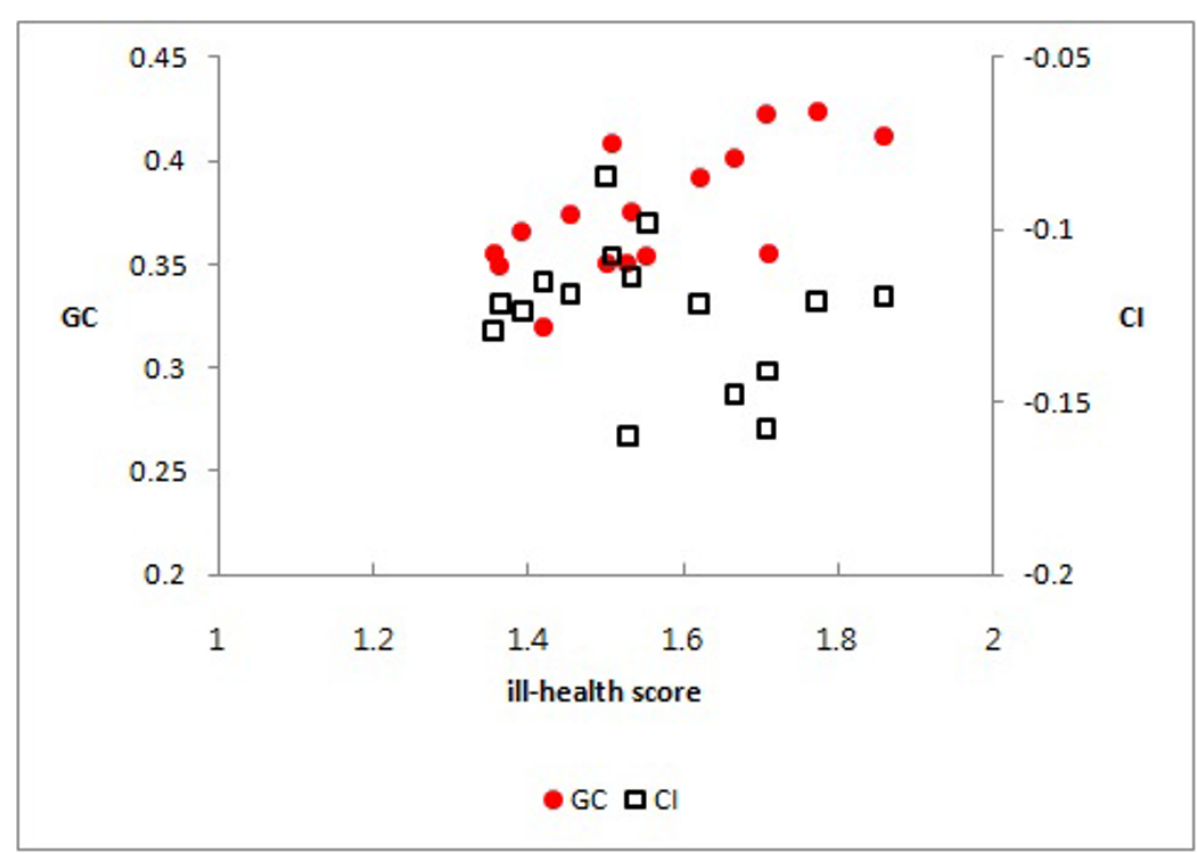

Figure 5 The GC (left) and the $\mathrm{Cl}$ (right) plotted against ill-health scores. The y-axis (left): The Gini coefficient. The y-axis (right): The Concentration Index. The x-axis: III-health scores.

particular, the absolute value of the $\mathrm{CI}^{*}$ increased when the GC increased. Income and health inequalities moved in the same direction, suggesting that a decrease in income inequalities may reduce socioeconomic health inequalities.

The overall GC was 0.376 (Table 5), which was slightly larger than those (0.31-0.32) reported by Kim et al [26]. The spatial GC was 0.0657, which was smaller than the overall GC but consistent with Park and Yu's [27] estimates ranging from 0.06-0.12. The smaller

Table 7 Regression estimates of health inequalities across regions

\begin{tabular}{lllll}
\hline dep. var. & intercept & GC & income & $\mathbf{R}^{\mathbf{2}}$ \\
\hline $\mathrm{GC}$ & 0.4945 & & -0.0181 & 0.304 \\
& $(<.0001)$ & & $(0.0268)$ & \\
$\mathrm{Cl}$ & -0.1510 & & 0.0042 & 0.051 \\
& $(0.0004)$ & & $(0.3985)$ & \\
$\mathrm{Cl}$ & -0.1248 & & 0.0107 & 0.385 \\
& $(0.0002)$ & & $(0.0104)$ & \\
$\mathrm{Cl}$ & -0.0661 & -0.1518 & & 0.072 \\
& $(0.2425)$ & $(0.3143)$ & & \\
$\mathrm{Cl}$ & 0.1051 & -0.4237 & & 0.655 \\
& $(0.0041)$ & $(0.0001)$ & & \\
\hline
\end{tabular}

Values in parentheses indicate the p-values of the estimates directly above. Cl: The $\mathrm{Cl}$ of ill-health scores.

$\mathrm{Cl}^{*}$ : The $\mathrm{Cl}$ of indirectly standardized ill-health scores by age and gender. GC: The Gini Coefficient. spatial inequalities may be due to the existence of sizable within-region inequalities.

All the CI values were negative, indicating that disadvantaged individuals and regions were less likely to be healthy. This result is consistent with the findings of previous studies [6,7]. The overall health inequality estimate was -0.1308 , and the age/gender-adjusted health inequality estimate was -0.059 (Table 5). The size of income-related health inequalities in Korea was similar to those of the Netherlands, Spain, and Switzerland but smaller than those for the U.S. and the U.K. [7]. The spatial CI was -0.0473 , and the age/gender-adjusted CI was -0.0282 . The spatial inequalities in health (like income inequalities) were smaller than the overall inequalities. This may be because we averaged the within-region variations in obtaining the special inequalities. As shown in Table 6 there were substantial income-related inequalities in health within regions (the CI ranged from -0.084 to -0.1596). In this regard, when devising and implementing policy initiatives to reduce regional inequalities in income and health, it is recommended for policymaker to take into account withinregion variations.

These results are consistent with the findings of previous studies considering different data sources. Previous study considering the Korea Labor Panel has reported various socioeconomic (education, job, and income) inequalities in mortality. Kang [2] have found regional 


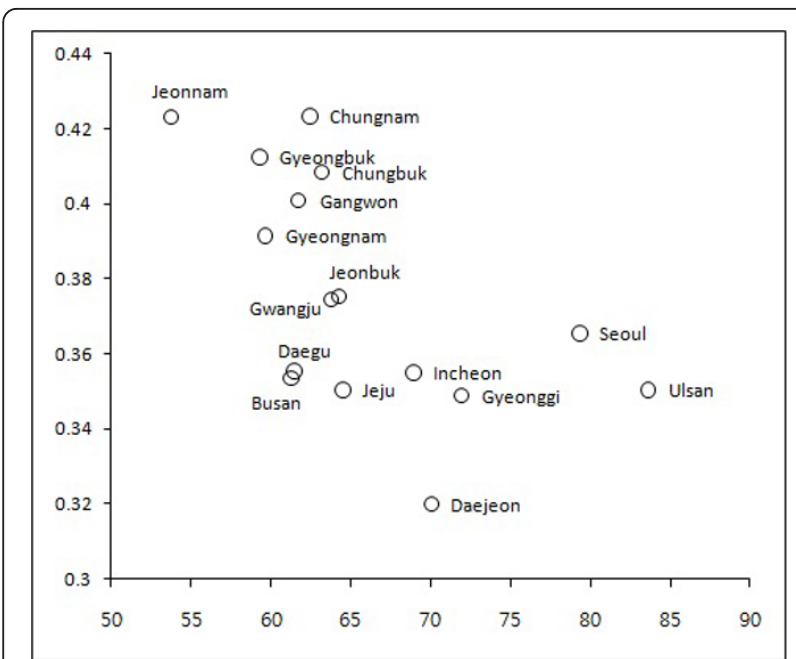

Figure 6 Within-province Gini coefficient and average income for 16 regions. The $x$-axis: Per capita income. The y-axis: The Gini Coefficient.

inequalities in mortality, demonstrating that highincome regions show lower mortality than low-income regions.

Both income and health inequalities were related to the level of health and income. The regions with poor average health were more likely to show large income inequalities and health inequalities than those with better health (Figure 5). Further, the GC was larger for low-income regions than for high-income ones (Figure 6). These results are consistent with the findings of previous studies demonstrating that groups/states with low quality of health are more likely to show large health inequalities. For example, Native Americans/ Native Alaskans had the lowest quality of health and faced the largest overall and income-related inequalities in health, and Kentucky and West Virginia had lowest quality of health and showed the largest inequalities in health [9].

In addition, there were strong relationships among the $\mathrm{CI}$, the GC, the level of income, and health status. The regression estimates indicate a negative relationship between the GC and the level of income; a positive relationship between the $\mathrm{CI}$ and the level of income; and a negative relationship between the $\mathrm{CI}$ and the GC (Table 7). The higher the region's average income, the smaller the region's income inequalities were. Further, an increase in the region's average income reduced its inequalities in health. This suggests that an increase in a region's average income reduces its income inequalities and that this leads to a more equitable distribution of health. Further, the larger a region's income inequalities, the larger the region's health inequalities are and vice versa.
Finally, the results reveal a possibility of convergence of socioeconomic inequalities in health across regions. Previous studies of income convergence across regions in Korea have produced mixed results. Some studies have found regional income convergence [28,29], noting a decreasing trend since the Asian financial crisis of 1997 [30], whereas others have provided no conclusive findings [31] or suggested the possible divergence of regional economies since the crisis [27]. In general, previous studies have indicated that regional income converged before the crisis but that it deteriorated or stagnated after the economic crisis. In the present study, both health and income inequalities were related to average per capita income, which suggests that these inequalities may show similar patterns. In sum, given a convergence of regional income to a higher level, regional health levels may follow a similar path, and health inequalities within/across regions may decrease.

\section{Conclusions}

Health inequalities have become an urgent social issue in many parts of the world, including advanced countries. For example, in the U.S., the Obama administration implemented an intense policy initiative to push government funded health insurance by stressing various negative effects of unequal access to health-care services on American health. Thus, the urgent need for reducing health inequalities across income groups and/or regions applies to all countries, including Korea.

The results indicate substantial socioeconomic inequalities in health both within and across regions. Previous studies have justifiably stressed the need for reducing huge inequalities across regions, but the results of the present study suggest the importance of reducing inequalities in health not only across regions but also within regions. Thus, although regional inequalities require proper attentions, policy initiatives should also focus on within-region variations in the distribution of health.

In terms of policy initiatives focusing on the welfare of the public, it is crucial to achieve economic growth while reducing socioeconomic inequalities in income and health within/across regions. However, since proportional growth, which leaves income inequalities unchanged, could lead to greater health inequalities [16], reducing socioeconomic health inequalities may require more progressive policy initiatives.

Any efforts to strike a balance between health equality and income growth should be based on long-term social goals, which is precisely the reason why there is an urgent need for assessing the current distribution of health. In this regard, future research should consider a wide range of health factors, regional characteristics, and policy objectives to better predict future inequalities in health both within and across regions. 
In addition, this study is based on pooled cross-sectional data, which make it difficult to determine causal relationships between health indicators and healthrelated factors. Therefore, longitudinal studies should be helpful for inferring the convergence of health inequalities across regions.

\section{Acknowledgements}

This research was supported by a grant from Yeungnam University in 2010 .

\section{Author details}

'Department of Senior Industry Management, Hanyang Cyber University Haengdang 1 Dong, Seongdong Gu, Seoul 133-791, Korea. ${ }^{2}$ School of Economics and Finance, Yeungnam University 280 Daehak-ro Kyungsan-si, Kyungbuk 712-749 Korea.

\section{Authors' contributions}

All the authors contributed to this research. BCA (the main author) was responsible for analyzing the data and prepared the manuscript. EJH participated in interpreting the results and revising the manuscript. This manuscript was approved by all the authors.

\section{Competing interests}

The authors declare that they have no competing interests.

Received: 25 April 2011 Accepted: 3 October 2011

Published: 3 October 2011

\section{References}

1. Statistics Korea. [http://kostat.go.kr]

2. Kang Y: Socioeconomic inequality in mortality from Korean Labor \& Income Panel Study (1998-2002). 2004 [http://www.kli.re.kr/_FILE/ REPORTPANELBOARD/4503e37c2ad75dd457860091 b4097f3d.pdf], (in Korean).

3. Park I, Lee D: Regional comparisons in medical service usages from national health insurance data: focusing cancer patients. Seoul: Health Insurance Policy Research Institute; 2010 [http://www.nhic.or.kr/cms/board/ Download.jsp?fileld=56927\&communityKey=B0069].

4. National Health Insurance Corporation: National Health Insurance Statistical Yearbook for 2009 Seoul: NHIC; 2010.

5. Park I: Regional comparisons in medical service usages between 2006-2008 Seoul: Health Insurance Policy Research Institute; 2009 [http://www.nhic.or. $\mathrm{kr} / \mathrm{cms} /$ board/Download.jsp?fileld=46232\&communityKey=B0070].

6. Kakwani N, Wagstaff A, van Doorslaer E: Socioeconomic inequalities in health: measurement, computation, and statistical inference. Journal of Econometrics 1997, 77(1):87-103.

7. van Doorslaer E, Wagstaff A, Bleichrodt H, Calonge S, Gerdtham U, Gerfin M, Geurts J, Gross L, Hakkinen U, Leu R, O'Donnell O, Propper C, Puffer F, Rodriguez $\mathrm{M}$, Sundberg $\mathrm{G}$, Winkelhake $\mathrm{O}$ : Income-related inequalities in health: some international comparisons. Journal of Health Economics 1997, 16:93-112.

8. Doran T, Drever F, Whitehead M: Is There a North-South Divide in Social Class Inequalities in Health in Great Britain? Cross sectional study using data from the 2001 census. British Medical Journal 2004, 328:1043-1045.

9. Lahiri K, Pulungan Z: Between and Within-Groups Health Inequality in the U.S. Population. Discussion papers, Department of Economics, State University of New York at Albany 2006.

10. Yu M, Sarri R: Women's health status and gender inequality in China. Social Science \& Medicine 1997, 45(12):1885-1898.

11. Liu Y, Hsiao W, Eggleston K: Equity in health and health care: the Chinese experience. Social Science \& Medicine 1999, 49(10):1349-1356.

12. Gao J, Tang S, Tolhurst R, Rao K: Changing access to health services in urban China: implications for equity. Health Policy and Planning 2001, 16(3):302-312.

13. Wu J, Liu Y, Rao K, Sun Q, Qian J, Li Z: Education-Related Gender Differences in Health in Rural China. American Journal of Public Health 2004, 94(10):1713-1716.
14. Zhang $X$, Kanbur R: Spatial Inequality in Education and Health Care in China. China Economic Review 2005, 16:189-204.

15. Ahn B, Engelhardt $\mathrm{K}$, Joung $\mathrm{H}$ : Income related health inequalities in Korea. Asia-Pacific Journal of Public Health 2010, 22(1):32-41.

16. Ourti T, van Doorslaer E, Koolman X: The effect of income growth and inequality on health inequality: Theory and empirical evidence from the European Panel. Journal of Health Economics 2009, 28(3):525-539.

17. Gerdtham U, Johannesson M, Lundberg L, Isacson D: A note on validating Wagstaff and van Doorslaer's health measure in the analysis of inequalities in health. Journal of Health Economics 1999, 18(1):117-124.

18. Fleurbaey M, Schokkaert E: Unfair inequalities in health and health care. Journal of Health Economics 2009, 28(1):73-90.

19. Erreygers G, Ourti T: Measuring socioeconomic inequality in health, health care and health financing by means of rank-dependent indices: A recipe for good practice. Journal of Health Economics 2011.

20. KNHANES. [http://knhanes.cdc.go.kr].

21. Karagiannis $E$, Kovacevic $M: A$ method to calculate the jackknife variance estimator for the Gini coefficient. Oxford Bulletin of Economics and Statistics 2000, 62(1):119-122.

22. Ogwang T: A convenient method of computing the Gini index and its standard error. Oxford Bulletin of Economics and Statistics 2000, 62(1):123-129.

23. Ogwang T: Calculating a standard error for the Gini coefficient: Some further results: Reply. Oxford Bulletin of Economics and Statistics 2004, 66(3):435-437.

24. Giles D: Calculating a standard error for the Gini coefficient: Some further results. Oxford Bulletin of Economics and Statistics 2004, 66(3):425-433.

25. Fang $P$, Donga $S$, Xiao J, Liud C, Feng $X$, Wang Y: Regional inequality in health and its determinants: Evidence from China. Health Policy 2010, 94(1):14-25.

26. Kim J, Kang S, Lee K: Time series analysis of income redistribution by within groups and between groups. Korean Journal of Public Finance 2009, 60:41-77, (in Korean).

27. Park S, Yu B: Inter-regional economic growth gap and IT industry concentration. Journal of Korean Economic Studies 2006, 15:199-226, (in Korean).

28. Koo J, Lee S: Regional Income Convergence Revisited. Korea international economic association 1999 winter conference proceedings: 1999; Seoul 1999, 1029-1042.

29. Kim H, Kim Y, Kim C: Human Capital and Regional Income Convergence in Korea using Nonstationary Panel Data. Journal of Korean Economy Analysis 2003, 9(2):109-164, (in Korean).

30. Moon C, Park K: Empirical Investigation into Regional Convergence in Korea. Korean Journal of Public Economics 2005, 10(2):49-79, (in Korean).

31. Yu B, Park S: Estimates and Convergence of Regional Human Capital. Journal of Korean Economic Studies 2004, 13:81-110, (in Korean).

doi:10.1186/1475-9276-10-41

Cite this article as: Hong and Ahn: Income-related health inequalities across regions in Korea. International Journal for Equity in Health 2011 10:41.

\section{Submit your next manuscript to BioMed Central and take full advantage of:}

- Convenient online submission

- Thorough peer review

- No space constraints or color figure charges

- Immediate publication on acceptance

- Inclusion in PubMed, CAS, Scopus and Google Scholar

- Research which is freely available for redistribution 